perimental production of congenital malformations in rodents by decreased partial pressure of oxygen which is one factor operative at high altitudes," by chronic audiovisual stress, ${ }^{2}$ and by other forms of maternal stress. ${ }^{ \pm}$

As a general conclusion, therefore, there would seem to be a greater likelihood of obtaining new information, or suggestions for further studies, from prospective epidemiologic investigations in which the bias of the investigator has become incorporated judiciously into a working hypothesis, along with a critical selection of factors for measurement and study. This current report may be regarded as providing an unbiased base line for such studies, even though its own conclusions are disappointingly few.-AlleN S. Goldyan, M.D., Children's Hospital of Philadelphia, Philadelphia. Pa. 19146.

\section{References}

1. Abramowicz, M. and Kass, E. H.: Pathogenesis and prognosis of prematurity. New Eng. I. Med. 275: $878,1966$.

2. Geber, W. F.: Developmental effects of chronic mat ternai audiovisual stress on the rat fetus. J. Embryol. Exp. Morphol. 16: 1, 1966.

3. Gentry, J. T., Parkhurst, E. and Bulin, G. V., Jr.:
An epidemiologic study of congenital malformations in New York State. Amer. J. Public Health 49: $497,1959$.

4. Goldman, A. S.: Predisposing genetic and metabolic factors to developmental defects of the central nervous system. I. Amer. Phys. Therap. Assn. 45: $4,345,1965$.

5. Ingalls, T. H. and Philbrook, F. R.: Monstrosities induced by hypoxia. New Eng. J. Med. 259: 558 , 1958.

6. Mckay, R. J. and Lucey, J. F.: Neonatology. New Eng. J. Med. 270: 1291, 1964.

7. Mellin, G, W.: Fetal life study. A prospective epidemiologic study of prenatal influences on fetal development. Bull. Soc. Roy. Belg. Gynec. Obstet. 33: 79, 1963.

8. Polman, A.: Genctica 25: 29, 1951.

9. Ravenholt, R. T., Levinski, M. J., Nellist, D. J. and Takenaga, M.: Effects of smoking upon reproduction. Arrer. J. Obstet. Gynec. 96: 267, 1966.

10. Stevenson, A. C., Johnston, H. A., Stewart, M. I. P. and Golding, D. R.: Congenital malformations, a report of a study of series of consecutive births in 24 centres, Suppl. to vol. 34 of the Bull. of W.H.O., Geneva, 1966.

Recipient of Career Development Award 1-K3-HD13,628 from the USPHS.

Supported in part by a research grant (P-355) from the American Cancer Society and (AM-10521) from the USPHS.

\title{
Psychoactive Drugs in the Treatment of Children's Emotional Problems
}

$W_{\text {H }}$

child? The emotional problems of children is well known and is highlighted by these three factors: (1) The number of drugs on the market. (2) the symptom which is to be the focus of the drug therapy, and (3) the personality of the child. The reaction of the child's family to his being given "a pill" further complicates the picture.

The number of medications which are potentially usable for the treatment of children's emotional ills is staggering. The basic differences between them is much less impressive, however, since there are a few broad categories of psychotropic drugs into which most of them fall. They include the tranquilizers which can be divided into minor and major; the sedatives; and the antidepressants. Further differentiation within each category is possible but not necessarily satisfactory. The minor tranquilizers are those commonly used for the control of anxiety or its derivatives, such as phobic reactions or obsessional behavior. Typical of this group are the meprobamates, the hydroxyzines, and the derivatives of diazepoxide. The major tranguilizers, although used also for anxiecy, are more commonly thought of as anti-psychotic agents. The most notable of these drugs are the phenothiazines. Time honored are the sedatives, which have been used often and where the new drugs occasionally fail. Probably the best known are the barbiturates and diphenhydramine. The antidepressants are best separated into mood 
elevators and stimulants. The mood elevators include monoamine oxidase inhibitors, imipramine, and the tryptilines. The stimulants characteriscically used with children are the amphetamines and, more recently, methylphenidate. Occasionally anticonvulsants are given for behavior disorders of children, but these are not generally classified with the tranquilizers. The physician is wise to know a few drugs very well and use these with confidence and knowledge of results, rather than experimenting for bimself on each child with a new or different medication.

Because the usual reason for prescribing a drug is to attempt to control specific behavior or feelings, a discussion of symptoms and drugs specific for these symptoms seems appropriate.

(1) Anxiety. In children, this is manifested by generalized fearfulness, nervousness, specific phobias, obsessional ideas, somatic complaints, or wakefulness. If this problem is not complicated by others, these children respond to the minor tranquilizers or a sedative, especially if nighttime fears and wakefulness are involved. Sometimes the anxiety is less tractable and requires one of the major tranquilizers.

(2) Hyperkinetic Behavior. These children manifest their difficulties with hyperactivity, distractibility, impulsivity and emotional lability. The initial drug of choice here is one of the stimulants. Both types can be tried, since if one doesn't work the other may. If neither works, dyphenhydramine becomes a good third choice. The major tranquilizers can be held in reserve and given in a final effort for control of the hyperkinesis.

(3) Aggressive Behavior. The child who impulsively strikes out to injure others and destroy property demands rigorous control. Often the major tranquilizers are sufficient to control this behavior. If the aggressive behavior is part of a hyperkinetic picture, the stimulants can be useful. An anticonvulsant can be tried if there are some evidences of EEG changes, including bursts of high frequency activity and 6 and 14 cycle per second rhythm.

(4) Bizarre Behavior. This behavior includes regressed, manneristic, withdrawn, delusional, hallucinatory, and primitive elements. Typically this is seen in the psychotic child. These symptoms respond most frequently to the major tranquilizers.

(5) Depression. Overt depression as seen in adults is uncommon in children but is more fre. quently seen as the age level reaches adolescence. In the younger child oher symptorns occur which are based on depression. These include self-punitive behavior (accident proneness or frequent mis. deeds for which he is caught), imritability, ease of crying, self-derogation, loss of appetite, acting up, and withdrawal. These symptoms respond to antidepressants; monoamine oxidase inhibitors are infrequently used with children. When there is agi- tated behavior, stimulants are often effective. The use of a combination of imipramine and a stimu. lant has been described as effective.

(6) Enuresis. This rather specific symptom of either daytime or nighttime enuresis often responds to the mood elevator, imipramine. It has also been known to give way to the stimulants.

The administration of any or all of these drugs would be simplified if they were highly specific for the symptoms and would have no other effect upon the child. Unfortunately (or fortunately), the child feels the effects more broadly than in the single symptom. These medications tend to affect the central nervous system within more than one area at the same time. Many other effects are felt by the child and in some way he must adjust to them. For instance, to quiet the autonomic expression of anxiety some sedation of the cortex must be suffered; to quell the hal. lucinations some extrapyramidal effect may require further medication. For the child the latter symptoms may be as perturbing as were the former to his parents or physician.

Psychological responses can be zaried. One child may be told that he cannot control his symptoms and, therefore, a medication is being given which can. Because of this the child may see himself as inadequate and become quite dependent on the medication. Another child may see the medicine as an expression of the physician's kindness and warmth, and respond to this more than to the drug itself. Still another child may feel because of side effects that the drug is a poison and either refuse to take it or show no response. At any rate, each child notes the act of being given a drug and taking it into his psychological make-up he develops a meaning for it all his own. It is wise to have explored some of these possibilities and to have some estimate of their effect ahead of time. The attempt should also be made to help the child understand clearly the reasons for the medication, as well as some of its effects. This demands talking with the child both about himself as well as about the drug.

The effects of drug treatment do not end within the child, since the family feels the impact in as many diverse ways as he does. The relation between the parents and child changes. The child's behavior, previously seen as annoying, now takes on the character of a sickness, for this is why medicine is given. The possibilities for further conflict and struggle are laid open by the parent having to see to it that the child takes the pill. Parents often worry about the addicive qualities of psychoacive drugs, and this can be communicated to the child. They, too, may feel inadequate because they cannot control their child's behavior and have to resort to a pill.

The result of the medication can both benefit family interaction and impair it. Where the child is more tractable, the attitudes toward him and 
the tension in the home can improve dramatically. Where the parents were relying upon the child's symptoms to support their own difficulties, the improvement can be disruptive. Hence the physician must have some understanding of the fam. ily's interactions to adequately predict the outcome of drug administration, and the family must be alerted to the probable changes.

Considering all of the above, giving a tranquilizer becomes a rather broad and complex act. A variety of observations must be taken both before and during the drug administration. It becomes important not only to know the drug and what symptoms will be affected by it, but also to gain some insight into how the child views the medication and to observe what interaction develops within the child's family.-JOEL P. ZRULL: M.D., Assistant Professor in Department of Psychiatry, University of Michigan Medical School; Director, Out-Patient Services, Children's Psychiatric Hospital, University of Michigan Medical Center, Ann Arbor, Michigan 48104.

\section{A New Attitude Needed in Public Education}

T

HAT the male and female mature at different rates should give us pause for considering the appropriate method of coping with educational processes. Studies in child growth and develop. ment show that in intellectual development boys have a lag of six months to one year at the time they enter school. Consequenty, what are the results of insisting that we teach boys at the same rate and in the same manner? Some results may perhaps be obseryed by taking a sample of boys and girls who are in high school. We observe such phenomena as four-to-one ratios of boys to girls in terms of recommendations for remedial read. ing; in terms of boys to girls referred for problems of juvenile delinquency and other behavior diff. culties; in terms of dropping out of school.

Knowledge of human growth and development tells us that there are optimum times for us to learn. That a child may or may not be able to learn to read at age two or age three is, to me, irrelevant; just because he is able to does not mean that he should. Many studies indicate that an attempt to speed up the learning process only results in frustration and in a tendency to develop antipathy toward this activity.

Miay I also suggest that we look at some of the newer educational methods in relationship to learning, with a prime example of this being the "new math." It is interesting to note that the "new math" gives few problems to the students but many to teachers and parents. It is always evident that the so-called dead hand of the past lies clammily upon the present.

In our understanding of a changing society we should be more flexible. That society is constantly changing tends to introduce feelings of misgivings within all of us. The world that our children will grow up and live in will be different in many dimensions from that of today.

Our role in the public school is to provide the kinds of tools and knowledges essential to coping with a complex industrial society. It is highly improbable that factual knowledge can be provided in terms of present understandings which will enable one to do this. There are no cookbooks for the future. Instead of worrying about cramming isolated facts into our children's heads, we should worry about building within them attitudes, feelings, emotions, and skills in basic learning skill areas, so that they will be able to cope wth any of the forms which the society of the future may develop into.-Leonard T. Curtis, Ed.D., Associate Professor of Education, Education for Exceptional Children, Thiversity of Virginia, Chanlottesmille, Va. 22901. 